\title{
Rice flour physically modified by microwave radiation improves viscoelastic behavior of doughs and its bread-making performance
}

\author{
Marina Villanueva ${ }^{a}$, Joanna Harasyma, ${ }^{\mathrm{a},}$, José $\mathrm{M}^{\mathrm{a}}$ Muñoz ${ }^{\mathrm{c}}$, Felicidad Ronda ${ }^{\mathrm{a}^{*}}$ \\ ${ }^{a}$ Department of Agriculture and Forestry Engineering, Food Technology, College of Agricultural and \\ Forestry Engineering, University of Valladolid, Spain \\ ${ }^{\mathrm{b}}$ Bio-Ref Lab, Department of Biotechnology and Foods Analysis, Institute of Chemistry and Food \\ Technology, Faculty of Engineering and Economics, Wrocław University of Economics, Wrocław, \\ Poland. \\ ${ }^{\mathrm{c}}$ Department of Electricity and Electronics, University of Valladolid, Valladolid, Spain \\ *Corresponding author: Av. Madrid, s/n, 34004, Palencia, Spain, fronda@iaf.uva.es
}

\begin{abstract}
The physical modification of rice flour by heat-moisture treatment assisted by microwave radiation and its effect on the rheological and pasting properties of glutenfree doughs and the physical quality of their resulting breads was investigated. Two levels of flour initial moisture content, 20\% (MW-20\%) and 30\% (MW-30\%) and two levels of its addition (30\% and 50\%) to the dough were evaluated to assess the potential of the physical treatment to modify dough viscoelasticity and bread-making ability. MW-30\% treated rice flour showed the most notable results. It provided enhanced dough viscoelasticity $v s$ the control (100\% native rice flour), increasing the dough $\mathrm{G}_{1}$ ' modulus up to $69 \%$ and $135 \%$ for the treated flour additions of $30 \%$ and $50 \%$ of MW$30 \%$ respectively. The treated flour increased the resistance of doughs to deformation and enhanced their elastic behavior and recovery capacity up to $170 \%$ when compared to the control dough. The major effects on pasting parameters were also obtained for the doughs formulated with MW-30\% flour at the maximum substitution level (50\%). It delayed the pasting temperature, decreased the peak, trough and final viscosities with respect to the control dough. Both MW-treated rice flours (MW-20\% and MW-30\%) led to breads with higher-specific volume, softer crumb and delayed staling. The MW assisted heat moisture treatment of rice flour seems to be a valuable procedure to improve the viscoelastic behavior and bread-making performance of gluten-free doughs.
\end{abstract}

Keywords: Microwave treatment, Rice flour, Dough rheology, Pasting properties, Gluten-free bread. 


\section{Introduction}

Rice flour is one of the most suitable ingredients for gluten-free (GF) bakery formulations due to the absence of gluten in its protein composition. Its hypoallergenic properties, bland taste, white colour, low protein and sodium content, as well as the presence of easily digested carbohydrates, are some of the benefits of this raw material (Rosell, Barro, Sousa, \& Mena, 2014). These characteristics encompass simultaneously some structural problems such as weak protein-starch network building capacity and the inability to sufficiently retain gas bubbles during fermentation. Several strategies have been developed to alleviate the rice flour dough formation problems, such as the addition of structure creating hydrocolloids (Ronda et al., 2013), nutritionally relevant fibers (Pérez-Quirce et al., 2014), external proteins (Crockett et al., 2011; Ziobro et al., 2013), emulsifiers (Demirkesen et al., 2010), enzymes (Amin et al., 2017; Renzetti and Rosell, 2016), dough acidification (Villanueva et al., 2015; Ronda et al., 2014) or emulsion formation (Yano et al., 2017). Other methods focus on physical modification of functional properties of rice flour by heat moisture treatment (HMT) that consists of heat undergoing different moisture levels (Bourekoua et al., 2016; Puncha-Arnon and Uttapap, 2013; Qin et al., 2016) or heat-pressure treatment (Cappa et al., 2016; Xu et al., 2016).

Thermal treatments deliver the possibility to impact both nutritional and functional properties during processing, as changing moisture and thermal conditions create an environment for different micro and macroscopic changes of complex matrix of flour (BeMiller and Huber, 2015). However, typical heat application results in high potential costs of industrial scaling up. Meanwhile, application of microwaves (MW) as heat providing media seems to be reasonable from both cost and functionality effectiveness change perspectives (Wu et al., 2008; Xu et al., 2013). Our previous studies investigated the application of microwave energy to rice flour for $\beta$-glucanase inactivation and enhancement of $\beta$-glucans bioactivity of fortified rice-based gluten-free breads (PérezQuirce et al., 2017) while bread physical quality was hardly affected by flour MW pretreatment. In fact, only a slightly higher loaf specific volume was noted for breads made from the most intensively treated flour (4 min of MW treatment at 25\% moisture content and $96^{\circ} \mathrm{C}$ maximum temperature reached by flour). No significant change was observed in the pasting properties of the treated flours.

It is known that more intense microwave assisted heat moisture treatment can change the functional properties of starches (Anderson and Guruya, 2006, Villanueva et al., 
2018c) but since there are substantial differences between a starch and a flour, in a previous study we have investigated its impact on rice flour characteristics (Villanueva et al., 2018a). The effect of microwave assisted thermal treatment was studied in relation to the initial moisture content $(20 \%$ and $30 \%)$ of treated-rice flour. The microwave radiation absorption capacity of flour, the moisture change during the treatment, the particle morphological structure as well as crystallinity/amorphous region ratio and flour thermal properties were studied revealing significant gelatinization temperature rise and the amylopectin retrogradation extent in treated-flours. The treatment resulted in lower viscometric profiles, amylose retrogradation and higher pasting temperatures (Villanueva et al. 2018a). The influence of this microwavedtreated rice flour on the viscoelastic behavior and bread-making performance of glutenfree rice based doughs seems necessary to be determined and has not been studied so far.

The objectives of this study were to evaluate the changes in fundamental rheological properties of doughs in which native rice flour was partially substituted by microwavetreated one as well as the impact of this new ingredient on the quality of the gluten-free bread. These results will complement our previous study (Villanueva et al., 2018a) and provide well-structured knowledge on how the microwave treatment of moistened rice flours changes its bread-making properties.

\section{Materials and Methods}

\subsection{Rice flour}

Indica rice variety (long grain) flour provided by Herba NAT 300 (Herba Ricemills S.L.U., Valencia, Spain) was used in this work. The moisture content was 13\%, ash $<1.0 \%$, protein: $8.13 \%$, fiber $<1 \%$; fat $<1 \%$. The granulometry of flour was as follows: $1 \%>250 \mu \mathrm{m}, 250 \mu \mathrm{m}>6.1 \%>210 \mu \mathrm{m}, 210 \mu \mathrm{m}>36.1 \%>150 \mu \mathrm{m}, 150 \mu \mathrm{m}$ $>33.4 \%>100 \mu \mathrm{m}$ and $26.6 \%<100 \mu \mathrm{m}$ (data provided by manufacturer).

\subsection{Microwave treatment of flour}

Native rice flour water content was measured with Official Method AACC 44-19.01 (AACC, 2010a) and the amount of water for reaching $20 \%$ and $30 \%$ of initial moisture content (IMC) levels was added. The calculated amount of water was sprayed onto the flour mixed in Teddy Bear mixer Mono Equipment (Swansea, UK) for $10 \mathrm{~min}$. The 
procedure used to perform the microwave treatment of the flour is described in Villanueva et al. (2018a). The microwave treatment time was 8 min applied in cycles of $20 \mathrm{~s} / 40 \mathrm{~s}$ of exposure and rest, respectively. The flour was continuously stirred by an external device at a speed of 60-70 rpm. The temperature evolution curves obtained for the rice flour studied were equivalent to those reported for 20 and $30 \%$ moistened-rice flour in our previous work (Villanueva et al., 2018a). The temperature reached and maintained after 4 min of MW-treatment was $157 \pm 5^{\circ} \mathrm{C}$ for all samples. Depending on the IMC of the treated rice flour $(20 \%$ or $30 \%)$, the MW treatment resulted in two different modified rice flours that were called MW-20\% and MW-30\%. Their final moisture content at the end of the treatment was $5.8 \%$ and $8.0 \%$ respectively. The MWtreated flours were further added to the dough in substitution of native rice flour at two different levels: $30 \%$ and $50 \%$ of to the total amount of flour used in the dough formulation.

\subsection{Dough preparation and bread-making}

A straight dough process was performed using the following formula on a $100 \mathrm{~g}$ rice flour (13\% moisture) basis: $1.5 \%$ salt, $2 \%$ HPMC, $5 \%$ sucrose, $6 \%$ oil and $95 \%$ water. The water added to the dough was adapted depending on rice flour moisture in order to get the same final dough hydration. Additional 3\% dried yeast dispersed in the water was used in the bread-making process. The GF dough and bread-making procedures are described in detail elsewhere (Pérez-Quirce et al., 2017). The dough (200 g) was placed into an aluminum pan and proofed at $30{ }^{\circ} \mathrm{C}$ and $90 \%$ relative humidity for $50 \mathrm{~min}$. Subsequently, baking was carried out at $170{ }^{\circ} \mathrm{C}$ for $20 \mathrm{~min}$ with steam injection for $7 \mathrm{~s}$ at the beginning of the process. Both, proofing and baking was carried out in Sveba Dahlen (SJ2/300 and S200 respectively) (Fristad, Sweden). After baking, the breads were removed from the pans and left for $1 \mathrm{~h}$ at room temperature before any analysis.

\subsection{Dough measurements}

\section{Oscillatory and creep recovery tests}

Oscillatory and creep-recovery tests were carried out with a Kinexus Pro+ rheometer (Malvern Instruments Ltd, UK) with parallel plate geometry (40 $\mathrm{mm}$ diameter) of serrated surface and with $1 \mathrm{~mm}$ gap. The excess of batter was removed and vaseline oil was applied to cover the exposed sample surfaces. Before the measurement, the dough was rested for 5 min to allow relaxation. Frequency sweeps were carried out from 20 to 
$0.1 \mathrm{~Hz}$ in the linear viscoelastic region (LVR) previously established for each batter by means of stress sweeps from 0.1 to $500 \mathrm{~Pa}$ at $1 \mathrm{~Hz}$. The frequency sweeps of all batters were carried out at stress values of $1 \mathrm{~Pa}$. Temperature was $25^{\circ} \mathrm{C}$. Frequency sweep data were fitted to the power law model as in previous works (Ronda et al., 2013).

The coefficients $G_{1}^{\prime}, G_{1}^{\prime \prime}$ and $(\tan \delta)_{1}$, represent the elastic and viscous moduli and the loss tangent at a frequency of $1 \mathrm{~Hz}$. The $a, b$ and $c$ exponents quantify the dependence degree of dynamic moduli and the loss tangent with the oscillation frequency, $\omega$. Creep tests were performed by imposing a sudden step shear stress in the LVR and outside the linear viscoelastic region (OLVR). For the creep study in the LVR, a constant shear stress of $1 \mathrm{~Pa}$ was applied for $150 \mathrm{~s}$, while in the recovery phase the stress was suddenly removed and the sample was allowed for $300 \mathrm{~s}$ to recover the elastic (instantaneous and retarded) part of the deformation. For the study OLVR, a constant shear stress of $50 \mathrm{~Pa}$ was applied for $60 \mathrm{~s}$ and the sample was allowed to recover for $200 \mathrm{~s}$ after removing the load. The data from creep tests were modelled to the 4-parameter Burgers model (Ronda, et al., 2014).

$$
J_{c}(t)=J_{0_{c}}+J_{1_{c}}\left(1-\exp \left(\frac{-t}{\lambda_{1 c}}\right)\right)+\frac{t}{\mu_{0}}
$$

In the equation, $J_{c}(t)$ is the creep compliance (strain divided by stress), $J_{0 c}$ is the instantaneous compliance, $\mathrm{J}_{1 \mathrm{c}}$ is the retarded elastic compliance or viscoelastic compliances, $\lambda_{1 \mathrm{c}}$ is the retardation time and $\mu_{0}$ gives information about the steady state viscosity. Similar equations were used for the recovery compliance $J_{r}(t)$. As there is no viscous flow in the recovery phase, equations consist only of parameters describing the elastic response after removal of the shear stress. The data from creep tests were modelled to the 3-parameter Burgers model given by:

$$
J_{r}(t)=J_{\max }-J_{0 r}-J_{1 r}\left(1-\exp \left(\frac{-t}{\lambda_{1 r}}\right)\right)
$$

$\mathbf{J}_{\max }$ is the maximum creep compliance obtained at the end of the creep step. The steadystate compliance in recovery step, $\mathrm{J}_{\text {steady, }}$ was also calculated by subtracting the compliance value at the terminal region of curve (where dough recovery reached equilibrium) from the $\mathbf{J}_{\max }$. The ratio $\mathbf{J}_{\text {steady }} / \mathbf{J}_{\max }$ (elastic recovery) was also calculated and expressed as Recovery (\%). Each rheological test was performed in triplicate.

\section{Pasting properties}


All the obtained doughs were lyophilized in Genesis Pilot Lyophilizer (SP Scientific, $\mathrm{Pa}$, USA) and the resulting solids where manually comminuted in mortar to less than $0.250 \mathrm{~mm}$. The pasting properties were studied using Kinexus Pro + rheometer (Malvern Instruments Ltd, UK) with starch pasting cell geometry using Standard 2 method 76-21.01 (AACC, 2010b). Rice flour samples (3 g, 14\% moisture basis) were transferred into the canister where $25 \mathrm{~mL} \pm 0.1 \mathrm{~mL}$ of distilled water was added. Each sample was analyzed at least in duplicate. The rSpace ver. 1.72 software (Malvern Instruments Ltd, UK) was used to calculate the pasting temperature (PT), peak viscosity $(\mathrm{PV})$, trough viscosity $(\mathrm{TV})$, breakdown $(\mathrm{BD}=\mathrm{PV}-\mathrm{TV})$, final viscosity $(\mathrm{FV})$ and setback (ST=FV-TV).

\subsection{Evaluation of bread quality}

The volume of bread was determined from two replicates using a Volscan profiler 300 (Stable Microsystems, Surrey, UK) analyzer. The breads were weighed immediately after removal from the pan once cooled to determine the baking loss.

Crumb texture was determined in quadruplicate with a TA-XT2 texture analyzer (Stable Microsystems, Surrey, UK) provided with the software "Texture Expert". An aluminium $20 \mathrm{~mm}$ diameter cylindrical probe was used in a "Texture Profile Analysis" double compression test (TPA) to penetrate $50 \%$ depth, at $1 \mathrm{~mm} / \mathrm{s}$ speed test, with a $30 \mathrm{~s}$ delay between the first and second compression. Firmness $(\mathrm{N})$, chewiness $(\mathrm{N})$, cohesiveness, springiness and resilience were calculated from the TPA graphic. Analysis was carried out at $(20 \pm 2)^{\circ} \mathrm{C}$ from two bread slices of $20 \mathrm{~mm}$ thickness taken from the centre of the loaf. Moreover, the differences in firmness values of breads between the fresh products and those after storage of 7 days ( $\Delta$ Firmness) at $(4 \pm 2){ }^{\circ} \mathrm{C}$ in hermetic bags were taken as a staling index.

Photographs of slices and side whole loafs were taken with PowerShot SX410 IS camera (Canon, Japan). Colour was measured with a Minolta spectrophotometer CN508i (Minolta, Co.LTD, Japan). Results were obtained in the CIE L*a*b* and CIE $\mathrm{L}^{*} \mathrm{C} * \mathrm{~h}$ coordinates using the D65 standard illuminant, and the $2^{\circ}$ standard observer. Colour determinations were made 5x5 times: bread crumb and crust colors were checked at five different points on each bread and every point was measured five times.

\subsection{Statistical analysis}


Statgraphics Centurion v.6 (Bitstream, Cambridge, MN, USA) was used for multivariate non-linear regression and Pearson correlation matrix. STATISTICA package (Tulsa, OK, USA) v.6, allowed performance of multi-factor analysis of variance (ANOVA) and LSD (Least Significant Difference) test was used to evaluate significant differences $(\mathrm{p}<0.05)$ between samples.

\section{Results and Discussion}

\subsection{Effect of MW-treated flour on dough properties}

\section{Dynamic oscillatory tests on doughs}

The impact of MW treated-rice flour substitution level (30\% and 50\%) and their IMC (20\% and $30 \%$ ) on doughs was studied by small amplitude oscillatory tests. Table 1 summarizes the coefficients $\mathrm{G}^{\prime}{ }_{1}, \mathrm{G}{ }^{\prime}{ }_{1}$ and $(\tan \delta)_{1}$, as well as the exponents $\mathrm{a}, \mathrm{b}$ and $\mathrm{c}$ obtained by fitting the power-law model to frequency sweep data. The high $\mathrm{r}^{2}$ values demonstrate the good adjustment of the systems studied to the model $\left(r^{2}>0.997\right)$. For all the studied samples the elastic modulus G' resulted in higher values than the viscous modulus $G$ ' providing values of $\tan \delta$ that ranged $0.49-0.64$. The ANOVA indicated a significant effect $(p<0.001)$ of the initial moisture content on $G^{\prime}{ }_{1}, G{ }^{\prime}{ }_{1}$ and $(\tan \delta)_{1}$. However, the level of substitution by MW treated flour did not revealed any significant effect. The interaction (level x IMC) affected significantly on $\mathrm{G}_{1}{ }_{1}$ which explains the increase of the elastic moduli with the level of substitution of MW-30\% flour substitution while no effect was observed with MW-20\%.

The control dough, made from $100 \%$ native rice flour, provided the lowest G' ${ }_{1}$ and $G$ ' ${ }_{1}$ values, nevertheless, they were not significantly different from the moduli of doughs made with MW-20\% rice flour regardless its substitution level. However, the addition of MW-30\% flour led to an increase in $\mathrm{G}^{\prime}{ }_{1}$ of $69 \%$ and $135 \%$, compared to the control dough, for the $30 \%$ and $50 \%$ addition level respectively. The viscous modulus, G' ${ }_{1}$, of doughs made with MW-30\% flour also increased (up to 78\%) vs. the control doughs and doughs with MW-20\%, although no significant differences were observed between the doughs with addition level (30\% or 50\%). Similar effects were noted on the loss tangent at $1 \mathrm{~Hz}$. The $(\tan \delta)_{1}$ values only varied significantly with respect to the control dough when MW-30\% treated-flour was added, regardless the addition level used. The loss tangent decreased in these doughs up to $24 \%$ denoting the ability of this MW-treated flour to increase the elastic behavior of bread doughs. 
Table 1. Effect of MW treated-rice flour substitution level (30\% and 50\% with respect to the total rice flour amount) depending on the treatment initial moisture content (MW-20\% and MW$30 \%$ ) on bread doughs viscoelastic properties obtained from oscillatory tests.

\begin{tabular}{|c|c|c|c|c|c|c|c|c|c|c|}
\hline \multirow{2}{*}{$\begin{array}{l}\text { Viscoelastic } \\
\text { properties }\end{array}$} & \multirow{2}{*}{$\begin{array}{l}\text { Level } \\
\text { (\%): }\end{array}$} & \multirow{2}{*}{$\begin{array}{c}\text { Control } \\
0 \\
\end{array}$} & \multicolumn{2}{|c|}{ MW-20\% } & \multicolumn{2}{|c|}{ MW-30\% } & \multirow[b]{2}{*}{$\mathbf{S E}$} & \multirow{2}{*}{$\begin{array}{c}\text { Factor 1 } \\
\text { Level }\end{array}$} & \multirow{2}{*}{$\begin{array}{c}\text { Factor } 2 \\
\text { IMC }\end{array}$} & \multirow{2}{*}{$\begin{array}{l}\text { Factor } 1 \text { x } 2 \\
\text { Level x IMC }\end{array}$} \\
\hline & & & 30 & 50 & 30 & 50 & & & & \\
\hline $\mathrm{G}_{1}^{\prime}(\mathrm{Pa})$ & & $1379 a$ & $1517 \mathrm{a}$ & $1404 \mathrm{a}$ & $2329 b$ & $3238 \mathrm{c}$ & 268 & $\mathrm{~ns}$ & $* * *$ & $*$ \\
\hline $\mathbf{a}$ & & $0.35 \mathrm{~b}$ & $0.35 b$ & $0.37 \mathrm{~b}$ & $0.31 \mathrm{a}$ & $0.29 a$ & 0.020 & $\mathrm{~ns}$ & $* * *$ & $\mathrm{~ns}$ \\
\hline $\mathbf{r}^{2}$ & & 0.999 & 0.999 & 0.9992 & 0.997 & 0.997 & & & & \\
\hline G', ${ }_{1}$ (Pa) & & $833 a$ & $946 a$ & $886 a$ & $1264 b$ & $1485 b$ & 139 & $\mathrm{~ns}$ & $* * *$ & $\mathrm{~ns}$ \\
\hline b & & $0.37 \mathrm{~b}$ & $0.35 \mathrm{a}$ & $0.39 b$ & $0.33 \mathrm{a}$ & $0.34 \mathrm{a}$ & 0.020 & $\mathrm{~ns}$ & $*$ & $\mathrm{~ns}$ \\
\hline $\mathbf{r}^{2}$ & & 0.999 & 0.999 & 0.999 & 0.998 & 0.999 & & & & \\
\hline$(\tan \delta)_{1}$ & & $0.64 b$ & $0.63 b$ & $0.63 b$ & $0.55 \mathrm{a}$ & $0.49 \mathrm{a}$ & 0.030 & $\mathrm{~ns}$ & $* * *$ & $\mathrm{~ns}$ \\
\hline c & & $0.027 \mathrm{a}$ & $0.005 \mathrm{a}$ & $0.017 \mathrm{a}$ & $0.023 a$ & $-0.015 a$ & 0.048 & $\mathrm{~ns}$ & $\mathrm{~ns}$ & $\mathrm{~ns}$ \\
\hline$\tau_{\max }(\mathbf{P a})$ & & $5.42 \mathrm{a}$ & $10.36 \mathrm{a}$ & $8.98 \mathrm{a}$ & $11.53 \mathrm{a}$ & $21.25 \mathrm{~b}$ & 4.5 & $\mathrm{~ns}$ & $\mathrm{~ns}$ & ns \\
\hline
\end{tabular}

IMC: Initial Moisture Content of the treated flour. MW-20\%: Rice flour treated at 20\% of Initial Moisture Content; MW-30\%: Rice flour treated at 30\% of Initial Moisture Content. The power law model was fitted to experimental results from frequency sweeps. $\mathrm{G}^{\prime}=G^{\prime}{ }_{1} \cdot \omega^{\mathrm{a}} ; \mathrm{G}{ }^{\prime}{ }^{\prime}=G^{\prime}{ }^{\prime}{ }_{1} \cdot \omega^{\mathrm{b}}$; $\left.\tan \delta=(\tan \delta)_{1} \cdot \omega^{\mathrm{c}}\right)$. $(\tan \delta)_{1}$ was obtained from the quotient $\mathrm{G}^{\prime}{ }_{\omega 1} / \mathrm{G}^{\prime}{ }_{\omega 1}$ and $c$ from $b$ - $a . . \tau_{\max }$ was obtained from stress sweeps. Different letters in the corresponding row indicate statistically significant differences between means at $\mathrm{p}<0.05$. SE: Pooled standard error obtained from ANOVA analysis. Analysis of variance and significance: $* * * p<0.001 . * * p<0.01{ }^{*} p<0.05$. ns: not significant.

Both moduli slightly increased with frequency in all the dough samples. The dependence of viscoelastic moduli on angular frequency, which is quantified by a and $b$ exponents, decreased significantly as result of MW-30\% addition (see Table 1) denoting more stable dough structures, regardless the addition level. However, the addition of MW-20\% flour did not have any effect on these values. The stronger structure of dough obtained with MW-30\% flour is coherent with the mayor changes observed in the functional properties of flour versus treated ones at higher IMC (Villanueva et al., 2018a). Pinkrova et al. (2003) also reported minimal changes resulting from MW treatment of rice flour at moisture below $23 \%$ while obtained significant reduction in the pasting peak viscosity when the moisture was 30\%. Authors related such behavior with the significant increase of damaged starch found in this flour as a result of the MW energy and the temperature reached during treatment. The increase of damaged starch would also explain an increase in the flour's water absorption capacity (Villanueva et al., 2018c) and the concomitant increase in dough consistency. 
a)

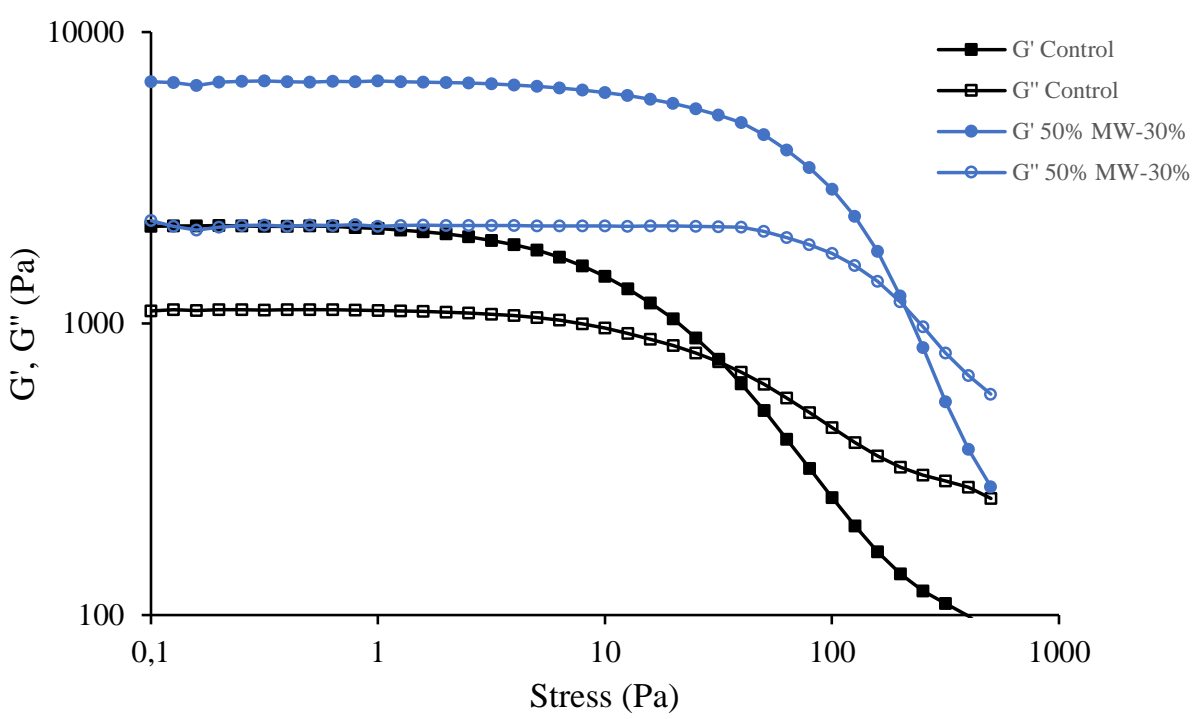

b)

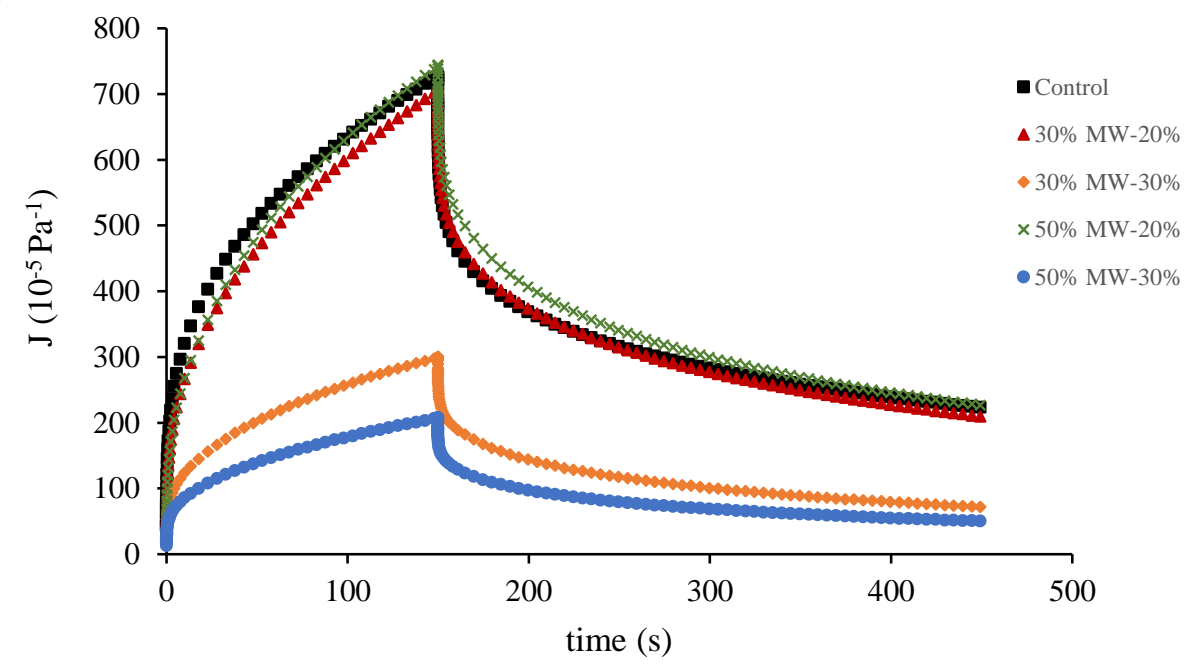

c)

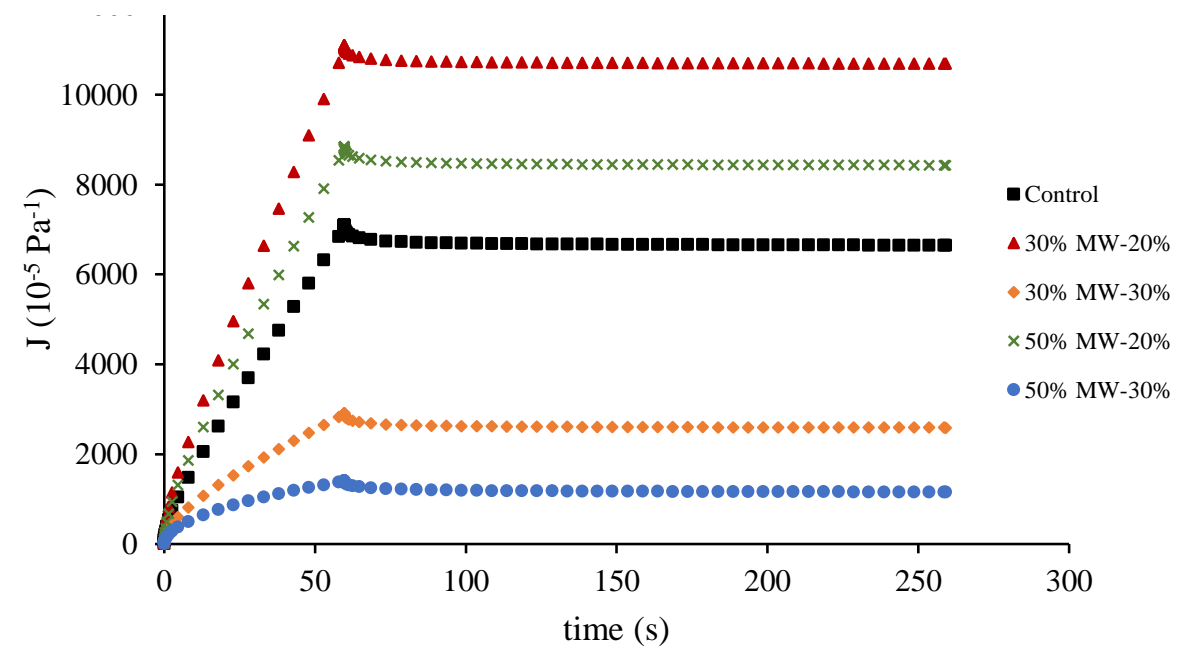

Figure 1: Effect of MW treated-rice flour substitution level (30\% and 50\% with respect to the total rice flour amount) and the initial moisture content (IMC) of the flour before the treatment: 20\% (MW-20\%) and 30\% (MW-30\%) on stress sweeps (a) and creep-recovery test of samples in the LVR (b) and OLVR (c) of bread doughs. Control. $\mathbf{\Delta} 30 \%$ of MW treated-rice flour addition with MW- $20 \%, 30 \% \mathrm{MW}$ treated rice flour addition with MW-30\%, $\square 50 \%$ MW treated rice flour addition with MW- $20 \%, \bullet 50 \%$ MW treated rice flour addition with MW-30\%. In stress sweeps, elastic modulus G', is represented by solid points and the viscous modulus G", by void points. 
Puncha-Arnon and Uttapap (2013) concluded a reordering of amylose and amylopectin within starch granules during heat-moisture treatments (at $100^{\circ} \mathrm{C}$ for $16 \mathrm{~h}$ at $20-30 \%$ moisture) of rice starch and flour. They also proposed the reinforcement of interactions between starch granules and proteins, denatured by heat. These molecular changes would justify the observed strengthening in bread doughs structure denoted by the viscoelastic moduli increase and the decrease of loss tangent.

The stress sweeps provide the $\tau_{\max }$ value or maximum stress that doughs were able to stand before the structure broke. The $\tau_{\max }$ values for all the doughs ranged from 5.4 to 21.3 Pa (Table 1). Fig. 1a shows the stress sweeps of the control dough and the dough with $50 \%$ of MW-30\% treated rice flour. These two samples showed the lowest and highest values of $\tau_{\max }$ respectively and again confirmed the stronger structuring effect of MW-30\% flour over the MW-20\% one. Results demonstrate that only when MW-30\% was added at $50 \%$ level the effect on $\tau_{\max }$ was significant. In general, as the initial moisture content and rate of addition increased, a greater structuring effect of the dough was determined. This could be due to the changes observed on structure, crystallinity, thermal and pasting properties of microwave treated samples, which were more pronounced with the higher levels of IMC (Villanueva et al., 2018a). Our previous results confirmed the suggestion made by Lewandowicz et al. (2000) that a higher gelatinization temperature of microwave irradiated starches may also indicate an association and a more stable configuration in a granular structure, resulting in higher values of ${ }^{\prime}{ }_{1}, G^{\prime}{ }_{1}$ and $\tau_{\max }$.

\section{Creep-recovery tests}

Creep-recovery tests were carried out at both $1 \mathrm{~Pa}$, within the linear viscoelastic region (LVR), and $50 \mathrm{~Pa}$, outside the linear viscoelastic region (OLVR). The Burgers model parameters obtained from these tests are summarized in Table 2. The stress values used for creep-recovery test in the LVR are often inappropriate to replicate real dough processing conditions because they are carried out in stress ranges very far from experienced by the dough during processing or baking expansion. However, those measurements are of great value in studying the influence of ingredients (Ronda et al., 2017). Creep-recovery curves of GF doughs exhibited a typical viscoelastic behavior combining both viscous and elastic components (Fig. 1b), similar to the corresponding 
curves previously obtained for rice flour (Sivaramakrishnan et al., 2004) and other gluten-free doughs (Lazaridou et al., 2007; Ronda et al., 2015; Villanueva et al., 2018b). In the LVR, a significant and strong correlation $(\mathrm{p}<0.001 ; \mathrm{r}=0.99)$ was found for both compliance parameters obtained in the creep phase, $\mathbf{J}_{0 c}$ and $\mathbf{J}_{1 \mathrm{c}}$, and the equivalents from the recovery phase $\left(\mathrm{J}_{0 \mathrm{r}}\right.$ and $\left.\mathrm{J}_{1 \mathrm{r}}\right)$. Besides, it was observed that factors providing an increase in viscosity at the steady state, $\mu_{0}$, decreased elastic and retarded elastic components, $\mathrm{J}_{0 \mathrm{c}}$ and $\mathrm{J}_{1 \mathrm{c}}(\mathrm{p}<0.05 \mathrm{r}=-0.97$ and $\mathrm{p}<0.01 ; \mathrm{r}=-0.98$ respectively).

Burgers model parameters obtained in the LVR were unaffected by the MW-20\% flour addition with the exception of the instantaneous elastic compliance, $\mathrm{J}_{0}$, which decreased (on average $\sim 18 \%$ ) with respect to the control dough, and the retardation time in the creep phase, $\lambda_{c}$, which increased $45 \%$ and $87 \%$ for the addition levels of $30 \%$ and $50 \%$ respectively. A higher retardation time means more time needed to obtain the viscoelastic deformation of the dough, even though the final deformation values were the same (not significantly different) in the control and MW-20\%-flour-added dough samples. However, the addition of MW-30\% flour led to a decrease in all compliance values when compared to the control dough $\left(59 \%, 67 \%\right.$ and $65 \%$ on average for $\mathrm{J}_{0 \mathrm{c}}, \mathrm{J}_{1 \mathrm{c}}$ and $J_{\max }$ respectively) and an increase in the steady viscosity $\mu_{0}(126 \%$ and $196 \%$ for the addition levels of $30 \%$ and $50 \%$ respectively). These results denote that the addition of MW-30\% treated flour increases the resistance of the bread doughs to deformation. The level of addition only affected significantly on the steady viscosity values of MW-30\% flour added-doughs, leading to an additional increase of $33 \%$ when the substitution level increased from $30 \%$ to $50 \%$.

The curves obtained from OLVR tests (Fig. 1c) correspond to materials with a much more predominant viscous component than the elastic one, as can be inferred from the almost direct proportionality between compliance and time in the creep phase, and the almost horizontal line obtained in the recovery step, particularly in the control dough and in the two MW-20\% flour added-doughs. The dough made with MW-30\% treated flour led to much lower curves, with higher elastic contribution than the control dough. Opposite to what was observed in the LVR, the OLVR curves allowed distinguishing among control and MW-20\% flour added-doughs. As can be seen in Table 2, the $\mathrm{J}_{\max }$ value obtained in MW-20\% flour added-doughs increased up to 56\% with respect to the control dough, while the viscoelastic compliance in the creep phase, $\mathrm{J}_{1 \mathrm{c}}$, increased up to $58 \%$. 
Table 2. Effect of MW treated-rice flour substitution level (30\% and 50\% with respect to the total rice flour amount) depending on the treatment initial moisture content (MW-20\% and MW-30\%) on bread doughs viscoelastic properties obtained from creep-recovery tests measured in the linear viscoelastic region (LVR) and outside the linear viscoelastic region (OLV).

\begin{tabular}{|c|c|c|c|c|c|c|c|c|c|c|c|}
\hline \multirow{2}{*}{$\begin{array}{l}\text { Viscoelastic } \\
\text { properties }\end{array}$} & & \multirow[b]{2}{*}{ Level (\%): } & \multirow{2}{*}{$\begin{array}{c}\text { Control } \\
0 \\
\end{array}$} & \multicolumn{2}{|c|}{ MW-20\% } & \multicolumn{2}{|c|}{ MW-30\% } & \multirow[t]{2}{*}{ SE } & \multirow{2}{*}{$\begin{array}{c}\text { Factor } 1 \\
\text { Level }\end{array}$} & \multirow{2}{*}{$\begin{array}{c}\text { Factor } 2 \\
\text { IMC }\end{array}$} & \multirow{2}{*}{$\begin{array}{c}\text { Factor 1x2 } \\
\text { Level } x \text { IMC }\end{array}$} \\
\hline & & & & 30 & 50 & 30 & $\mathbf{5 0}$ & & & & \\
\hline \multicolumn{12}{|c|}{ LVR Creep phase } \\
\hline $\mathbf{J}_{0 \mathrm{c}}$ & $\left(10^{-5} \mathbf{P a}^{-1}\right)$ & & $74 c$ & $59 b$ & $62 b$ & $35 \mathrm{a}$ & $26 a$ & 4.4 & $\mathrm{~ns}$ & $* * *$ & $\mathrm{~ns}$ \\
\hline $\mathbf{J}_{1 \mathbf{c}}$ & $\left(10^{-5} \mathbf{P a}^{-1}\right.$ & & $258 b$ & $237 b$ & $267 b$ & $97 \mathrm{a}$ & $71 \mathrm{a}$ & 26 & $\mathrm{~ns}$ & $* * *$ & ns \\
\hline$\lambda_{c}$ & (s) & & $3.8 \mathrm{a}$ & $5.5 \mathrm{~b}$ & $7.1 \mathrm{c}$ & $4.6 \mathrm{ab}$ & $4.9 \mathrm{ab}$ & 0.61 & $*$ & $* *$ & $\mathrm{~ns}$ \\
\hline$\mu_{\mathrm{c}}$ & $\left(10^{3} \mathrm{~Pa} \cdot \mathrm{s}\right)$ & & $42.6 \mathrm{a}$ & $42.7 \mathrm{a}$ & $37.6 \mathrm{a}$ & $94.9 \mathrm{~b}$ & $126.0 \mathrm{c}$ & 5.9 & $*$ & $* * *$ & $* * *$ \\
\hline $\mathbf{J}_{\max }$ & $\left(10^{-5} \mathbf{P a}^{-1}\right)$ & & $726 b$ & $667 b$ & $744 b$ & $288 \mathrm{a}$ & $210 \mathrm{a}$ & 67 & $\mathrm{~ns}$ & $* * *$ & $\mathrm{~ns}$ \\
\hline \multicolumn{12}{|c|}{ LVR Recovery phase } \\
\hline $\mathbf{J}_{0 \mathrm{r}}$ & $\left(10^{-5} \mathbf{P a}^{-1}\right)$ & & $142 \mathrm{c}$ & $122 b$ & $118 b$ & $61 \mathrm{a}$ & $45 \mathrm{a}$ & 6.8 & $\mathrm{~ns}$ & $* * *$ & $\mathrm{~ns}$ \\
\hline $\mathbf{J}_{1 \mathbf{r}}$ & $\left(10^{-5} \mathbf{P a}^{-1}\right)$ & & $334 b$ & $338 b$ & $376 b$ & $142 \mathrm{a}$ & $106 \mathrm{a}$ & 26 & $\mathrm{~ns}$ & $* * *$ & $\mathrm{~ns}$ \\
\hline$\lambda_{r}$ & (s) & & $54.2 \mathrm{ab}$ & $57.8 \mathrm{ab}$ & $61.1 \mathrm{~b}$ & $52.7 \mathrm{a}$ & $53.1 \mathrm{a}$ & 3.2 & ns & $*$ & ns \\
\hline Recovery & $(\%)$ & & $73 a$ & $74 a$ & $71 \mathrm{a}$ & $74 \mathrm{a}$ & $75 a$ & 3.3 & $\mathrm{~ns}$ & $\mathrm{~ns}$ & $\mathrm{~ns}$ \\
\hline \multicolumn{12}{|c|}{ OLVR Creep phase } \\
\hline $\mathbf{J}_{0 \mathrm{c}}$ & $\left(10^{-5} \mathbf{P a}^{-1}\right)$ & & $73 \mathrm{bc}$ & $88 \mathrm{c}$ & $81 \mathrm{c}$ & $64 b$ & $48 \mathrm{a}$ & 5.2 & $*$ & $* * *$ & $\mathrm{~ns}$ \\
\hline $\mathbf{J}_{1 \mathbf{c}}$ & $\left(10^{-5} \mathbf{P a}^{-1}\right)$ & & $597 \mathrm{a}$ & $944 b$ & $831 b$ & $567 \mathrm{a}$ & $481 \mathrm{a}$ & 51 & ns & $* * *$ & $\mathrm{~ns}$ \\
\hline$\lambda_{c}$ & $(\mathbf{s})$ & & $2.1 \mathrm{a}$ & $2.1 \mathrm{a}$ & $2.5 \mathrm{a}$ & $4.1 \mathrm{~b}$ & $5.9 \mathrm{c}$ & 0.28 & $* *$ & $* * *$ & $*$ \\
\hline$\mu_{\mathrm{c}}$ & $\left(10^{+3} \mathbf{P a} \cdot \mathbf{s}\right)$ & & $0.98 \mathrm{ab}$ & $0.60 \mathrm{a}$ & $0.78 \mathrm{a}$ & $2.71 b$ & $7.19 \mathrm{c}$ & 0.61 & $*$ & $* * *$ & $* *$ \\
\hline $\mathbf{J}_{\max }$ & $\left(10^{-5} \mathbf{P a}^{-1}\right)$ & & $7094 b$ & $11098 \mathrm{c}$ & $8837 b$ & $2903 a$ & $1403 \mathrm{a}$ & 68 & $*$ & $* * *$ & $\mathrm{~ns}$ \\
\hline \multicolumn{12}{|c|}{ OLVR Recovery phase } \\
\hline $\mathbf{J}_{0 \mathrm{r}}$ & $\left(10^{-5} \mathrm{~Pa}^{-1}\right)$ & & $61 d$ & $51 \mathrm{c}$ & $53 c$ & $42 b$ & $34 \mathrm{a}$ & 1.8 & $\mathrm{~ns}$ & $* * *$ & $*$ \\
\hline $\mathbf{J}_{1 \mathbf{r}}$ & $\left(10^{-5} \mathbf{P a}^{-1}\right)$ & & $368 c$ & $344 c$ & $339 c$ & $260 \mathrm{~b}$ & $202 a$ & 9.9 & $* *$ & $* * *$ & $*$ \\
\hline$\lambda_{r}$ & (s) & & $4.9 \mathrm{a}$ & $4.7 \mathrm{a}$ & $4.9 \mathrm{a}$ & $5.9 \mathrm{a}$ & $10.1 b$ & 0.53 & $* * *$ & $* * *$ & $* *$ \\
\hline Recovery & $(\%)$ & & $6.7 b$ & $3.7 \mathrm{a}$ & $4.8 \mathrm{ab}$ & $11.2 \mathrm{c}$ & $18.1 \mathrm{~d}$ & 0.90 & $* * *$ & $* * *$ & $* *$ \\
\hline
\end{tabular}

IMC: Initial Moisture Content of the treated flour. MW-20\%: Rice flour treated at 20\% of Initial Moisture Content; MW-30\%: Rice flour treated at 30\% of Initial Moisture Content. $\mathrm{J}_{0}$ and $\mathrm{J}_{1}$ are the instantaneous and retarded elastic compliances; $\lambda_{1}$ is the retardation time and $\mu_{0}$ the steady state viscosity. $J_{\max }$ is the maximum creep compliance obtained at the end of the creep step. Recovery is the elastic recovery obtained in the recovery phase expressed as percentage of the maximum compliance, $\mathrm{J}_{\max }$. Subscript c corresponds to parameters in the creep phase and subscript $\mathrm{r}$, in the recovery phase. Different letters in the corresponding row indicate statistically significant differences between means at $\mathrm{p}<0.05$. SE: Pooled standard error obtained from ANOVA analysis. Analysis of variance and significance: $* * * \mathrm{p}<0.001, * * \mathrm{p}<0.01, * \mathrm{p}<0.05$. ns: not significant. 
As could be expected, outside the linear viscoelastic region, where the stress applied overpasses the maximum stress the dough can stand without breaking its structure, the compliances obtained in the recovery phase were not significantly correlated $(p>0.05)$ with those of the creep phase.

The recovery capacity of doughs after releasing the applied stress, which is related to the contribution of the elastic deformation (the only one recoverable) with respect to the total deformation, decreased markedly from 71 to $74 \%$ in the LVR (without differences among the tested doughs) to $4-11 \%$, when the tests were performed OLVR. The doughs made with $30 \%$ and $50 \%$ of MW-30\% flour showed significantly stronger elastic behavior and, comparing to control, their recovery capacity increased $67 \%$ and $170 \%$ respectively. Since elasticity reflects the extent of bonding between the structural elements of the dough its increase could mean less deformation or breakage of the composite network, due to the MW-30\% treated flour presence in the dough (Skendi et al., 2009).

\section{Pasting properties}

The impact of MW assisted treatment on the viscometric parameters of bread doughs containing 30\% and $50 \%$ of treated flours is shown in Fig. 2 and Table 3. Quantitative viscometric profiles of the control dough during pasting and gelling were systematically higher as compared to doughs with $30 \%$ and $50 \%$ of MW-treated flour substitution. The major effects on cooking and cooling parameters were obtained for the doughs formulated with flours treated at $30 \%$ of IMC and at the maximum substitution level (50\%). Similar findings were reported for flours treated by MW-assisted heat moisture treatment (Villanueva et al., 2018a) or conventional heat moisture treatments (Zavareze and Dias, 2011). The addition of treated flour delayed the pasting temperature (PT) up to $5^{\circ} \mathrm{C}$ and $7^{\circ} \mathrm{C}$ for MW-20\% and MW-30\% doughs, respectively. It decreased the peak (15\% and 27\%), trough (8\% and 17\%) and final (5\% regardless the IMC of the treatment) viscosities with respect to the control dough. Such changes in pasting properties of doughs are due to heat-treated flour and have been attributed to associations between the polymeric chains in the amorphous regions of the starch granule as well as to changes in crystallinity caused by the hydrothermal treatment (Watcharatewinkul et al., 2009) which was confirmed by X-ray diffraction assays (Villanueva et al., 2018a). The structural modifications were found more pronounced as the flour moisture content increased before the hydrothermal treatment (Olayinka et al., 
2008). As the intragranular chain interactions were strengthen (annealing effects), the reorganized starch structures required more heat energy for structural disintegration and paste formation; i.e., a higher pasting temperature, as found in the current study (Table 3), indicates a more dense cross-linking within the starch granules of doughs.

Table 3. Effect of MW treated-rice flour substitution level (30\% and 50\% with respect to the total rice flour amount) depending on the treatment initial moisture content (MW-20\% and MW-30\%) on pasting properties of bread doughs

\begin{tabular}{|c|c|c|c|c|c|c|c|c|c|c|}
\hline \multirow{2}{*}{$\begin{array}{l}\text { Pasting } \\
\text { properties }\end{array}$} & \multirow[b]{2}{*}{$\begin{array}{r}\text { Level } \\
(\%):\end{array}$} & \multirow{2}{*}{$\begin{array}{c}\text { Control } \\
0\end{array}$} & \multicolumn{2}{|c|}{ MW-20\% } & \multicolumn{2}{|c|}{ MW-30\% } & \multirow[b]{2}{*}{ SE } & \multirow{2}{*}{$\begin{array}{c}\text { Factor } 1 \\
\text { Level }\end{array}$} & \multirow{2}{*}{$\begin{array}{c}\text { Factor } 2 \\
\text { IMC }\end{array}$} & \multirow{2}{*}{$\begin{array}{r}\text { Factor 1x2 } \\
\text { Level x IMC }\end{array}$} \\
\hline & & & 30 & 50 & 30 & 50 & & & & \\
\hline PV $\quad\left(10^{-3} \mathrm{~Pa}\right)$ & & $1607 \mathrm{e}$ & $1457 d$ & $1373 c$ & $1315 b$ & $1167 \mathrm{a}$ & 8.0 & $* * *$ & $* * *$ & $* *$ \\
\hline TV $\quad\left(10^{-3} \mathrm{~Pa}\right)$ & & $1090 \mathrm{e}$ & $1051 d$ & $997 b$ & $1015 c$ & $905 \mathrm{a}$ & 3.4 & $* * *$ & $* * *$ & $* * *$ \\
\hline BD $\quad\left(10^{-3} \mathrm{~Pa}\right)$ & & $519 \mathrm{e}$ & $406 \mathrm{~d}$ & $376 \mathrm{c}$ & $300 \mathrm{~b}$ & $261 \mathrm{a}$ & 8.0 & $* * *$ & $* *$ & ns \\
\hline $\mathrm{SB} \quad\left(10^{-3} \mathrm{~Pa}\right)$ & & $1102 b$ & $1157 d$ & $1086 a$ & $1128 \mathrm{~d}$ & $1165 d$ & 3.4 & $* * *$ & $* *$ & $* * *$ \\
\hline FV $\quad\left(10^{-3} \mathrm{~Pa}\right)$ & & $2189 d$ & $2208 \mathrm{e}$ & $2083 b$ & $2143 c$ & $2070 \mathrm{a}$ & 3.2 & $* * *$ & $* * *$ & $* * *$ \\
\hline PT $\left({ }^{\circ} \mathrm{C}\right)$ & & $86.1 \mathrm{a}$ & $89.7 \mathrm{~b}$ & $91.3 \mathrm{c}$ & $90.2 \mathrm{~b}$ & $92.9 \mathrm{~d}$ & 0.30 & $* *$ & $* * *$ & $\mathrm{~ns}$ \\
\hline
\end{tabular}

IMC: Initial Moisture Content of the treated flour.MW-20\%: Rice flour treated at 20\% of Initial Moisture Content; MW-30\%: Rice flour treated at 30\% of Initial Moisture Content.PV: peak viscosity; TV: trough viscosity; BD: breakdown viscosity, FV: final viscosity ST: setback viscosity (FV-TV). PT: pasting temperature. Different letters in the corresponding row indicate statistically significant differences between means at $\mathrm{p}<0.05$. SE: Pooled standard error obtained from ANOVA analysis. Analysis of variance and significance: $* * *$ $\mathrm{p}<0.001 . * * \mathrm{p}<0.01 . * \mathrm{p}<0.05$. ns: not significant.

The BD value decreased $28 \%$ and $49 \%$ for MW-20\% and MW-30\% respectively at the maximum level of addition (50\%). This change denotes an enhanced stability of doughs versus heating and stirring. Such changes can be explained by associations between chains in the amorphous region of the granules of the treated flour as well to changes in crystallinity during hydrothermal treatment (Zavareze and Dias, 2011). These results are consistent with those previously found in MW-treated rice flour (Villanueva et al., 2018a): the MW treatment of rice flour at $20 \%$ and $30 \%$ of initial moisture content for 8 min resulted in pasting temperature increases of $8^{\circ} \mathrm{C}$ and $11^{\circ} \mathrm{C}$ and decreases of peak (38\% and $42 \%)$, trough (9\% and 13\%), final (13\% and 25\%) and breakdown ( $81 \%$ and $86 \%$ ) viscosities, with respect to native flour. Considering the dilution effect of the MW-treated flour with native one in the studied doughs, a similar effect can be expected, for both the MW treatment and the IMC, on the pasting properties of flours and doughs formulated. Of course, the quantitative viscometric profiles of studied doughs were always significantly lower as compared to those previously reported for 
flour suspensions (Villanueva et al. 2018a) due to the presence of non-starch ingredients in the doughs, particularly HPMC and lipids.

a)

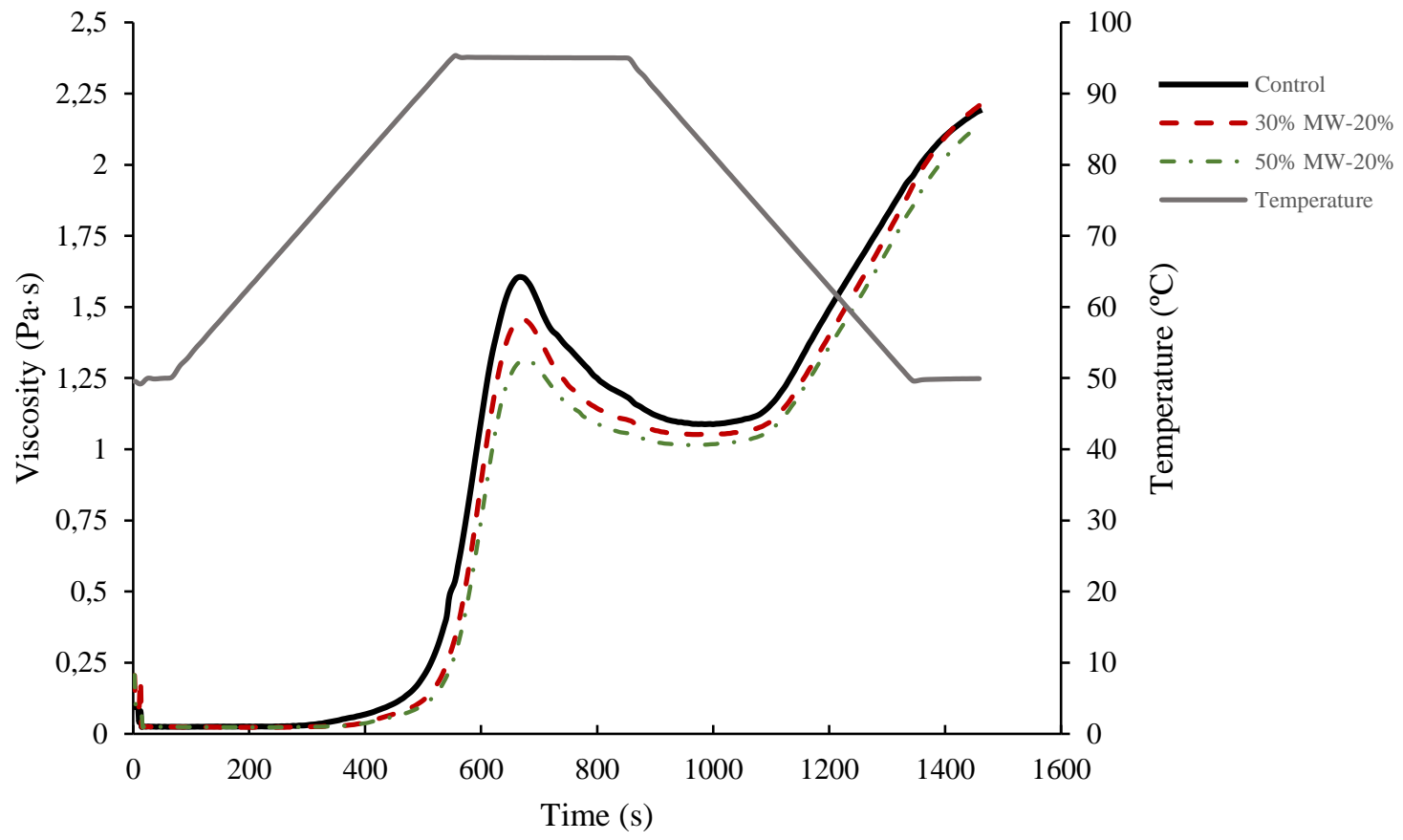

b)

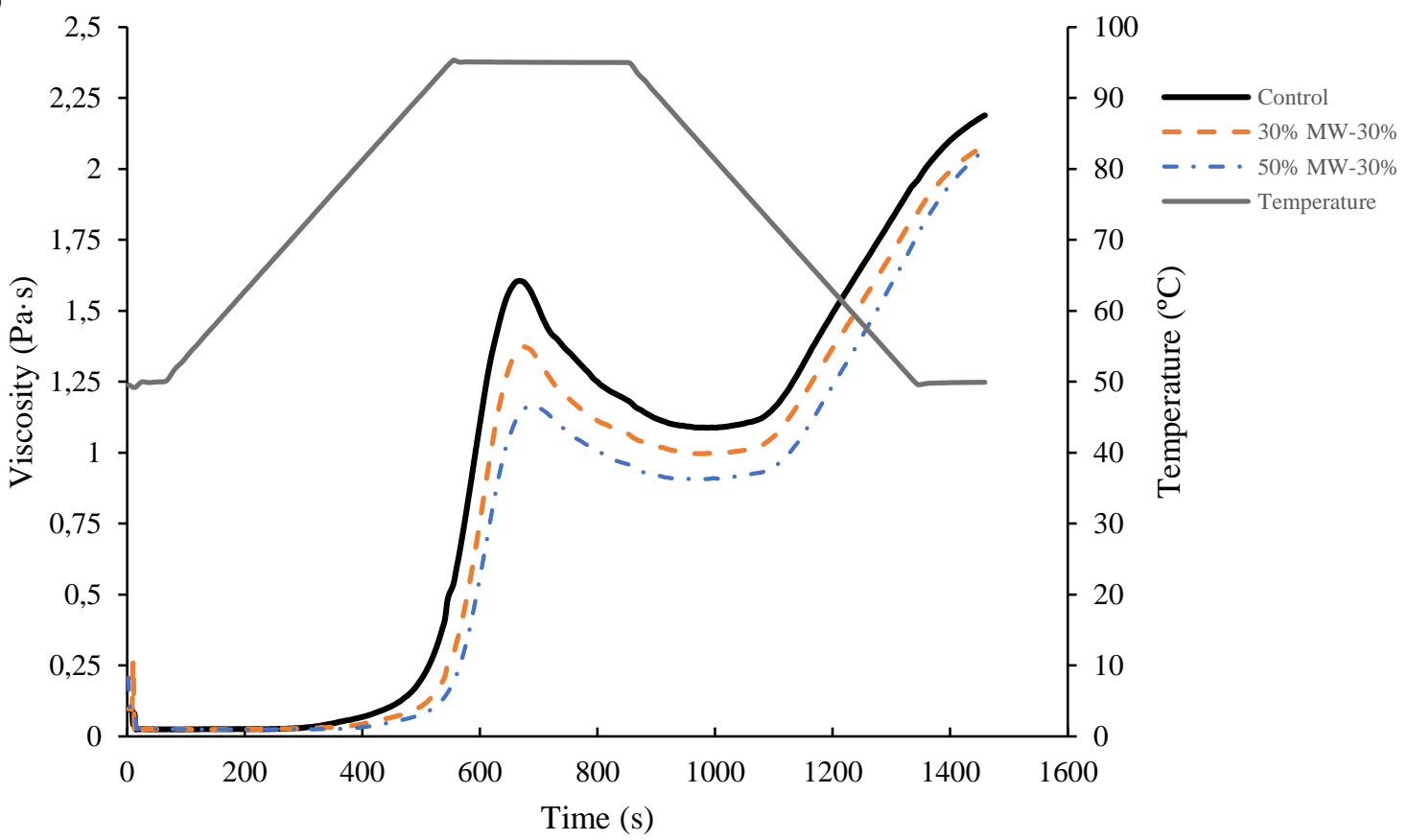

Figure 2: Pasting profiles of MW treated-rice flours depending on the treated-rice flour substitution level (30\% and 50\% with respect to the total rice flour amount) and the initial moisture content (IMC) of the flour before the treatment: a) IMC $=20 \%(\mathrm{MW}-20 \%)$ and b) $\mathrm{IMC}=30 \%(\mathrm{MW}-30 \%)$.

Control dough is represented by — with $50 \%$ of MW treated-flour by - - - . The temperature profile is represented by —— in the second axis. 
These ingredients and their dilution effect on starch, can restrict swelling and gelatinization during cooking, in good agreement with the lower viscometric pattern observed in blended matrices (bread doughs) compared to native flours (Villanueva et al., 2018b). Similar increases of pasting temperatures and decreases of pasting viscosities were also reported by Puncha-arnon and Uttapap (2013) for rice flours from HMT at 20\%, 25\% and 30\% of IMC and Majzoobi et al. (2016) for rice flour at 20\% of IMC. Greater effects were always obtained at the highest moisture content of the flour during the treatment as we have observed in our formulated bread doughs.

\subsection{Effect of MW-treated flour on bread quality}

Table 4 summarizes the effects of MW treated flour addition to dough formulation and the IMC of the flour on the physical properties of breads. The substitution of native rice flour by treated one always significantly improved bread specific volume which increased from $3.3 \mathrm{~mL} / \mathrm{g}$, for the control one, up to $4.6 \mathrm{~mL} / \mathrm{g}$ for breads with $50 \%$ of MW-20\% flour or 30\% of MW-30\% flour. The same tendency was previously observed by Pérez-Quirce et al. (2017) for breads made with rice flour irradiated with microwaves for beta-glucanase inactivation. In that case the increase in bread specific volume hardly reached $8 \%$ even in the most intense microwave treated flour because the maximum temperature reached by flour during those treatments was $96^{\circ} \mathrm{C}$, since the principal goal was the enzyme inactivation (instead of $157^{\circ} \mathrm{C}$ as was reached in the present study). The substitution level and the IMC of the treated flours, as well as their interaction (level x IMC), significantly affected $(p<0.001)$ the bread specific volume. The bread volume increased with the substitution level in the case of MW-20\% flour, while the opposite effect happened with the addition of MW-30\% flour. The improvement in structural strength and bread volume can be related to the increase in dough viscosity as a result of the MW treatment (Marston et al., 2016). A greater consistency of the dough helps to retain the gas formed during fermentation and prevents its coalescence and loss during both fermentation and baking, allowing a higher volume of bread. However, there is an optimal value of consistency. Excessive dough consistency may have detrimental effects and lead to smaller breads because the dough cannot sufficiently expand as a result of the pressure produced by the gas (Ronda et al., 2017). This would explain why doughs with $50 \%$ of MW-30\% treated flour, having higher $\mathrm{G}_{1}$ ' and $\mathrm{G}_{1}$ "' moduli and steady viscosity $\mu_{0}$ than doughs with $30 \%$ of the same flour, had led to breads of smaller specific volume. This explanation cannot be 
used to justify the effect of MW-20\% treated flour on bread volume. Doughs made with MW-20\% flour showed hardly any difference in viscoelastic moduli (Table 1), in compliance values or steady viscosities (Table 2) with respect to the control dough. The differences in pasting properties also explain the different bread volumes. The higher pasting temperature of doughs made with treated flour, would allow a greater development of the dough during baking before the fixation of the crumb structure upon baking (Ronda et al., 2017). In fact, the Pearson coefficient revealed a significant positive correlation between specific volume of breads and dough pasting temperature $(\mathrm{p}<0.01 ; \mathrm{r}=0.78)$ while a significant negative correlation between dough breakdown and specific volume $(\mathrm{p}<0.05, \mathrm{r}=-0.74)$ was also obtained. Similar correlation was found by Cornejo and Rosell (2015) from gluten-free breads obtained from different varieties of indica rice. From the previous section can be seen that BD values decreased gradually in doughs following the order: control > 30\% MW-20\% > 50\% MW-20\% > 30\% MW$30 \%>50 \% \mathrm{MW}-30 \%$. It would also contribute to explain the near opposite order in the bread volume evolution. A lower BD value means a higher stability of dough viscosity during heating, which also helps to retain the gas during baking, allowing a higher development.

The loss of weight during baking increased from $19 \%$ in the control bread, to $21-22 \%$ in breads made with treated flour regardless the IMC of the flours. The bake loss was positively correlated to bread specific volume $(\mathrm{p}<0.01 ; \mathrm{r}=0.89)$. Such correlation was previously found in rice based gluten-free breads where the effect of soluble fiber addition and dough hydration were studied (Pérez-Quirce et al., 2014). The higher development during baking of breads made with treated flour and the delayed pasting temperature of these doughs mean a higher surface exposed to dryness in the oven during a longer time, which could explain the positive correlation between baking loss and bread volume.

The use of MW treated rice flour led to breads of softer crumbs (Table 4). Crumb firmness decreased from $0.71 \mathrm{~N}$, for the control bread, up to $0.3 \mathrm{~N}$ in breads made with $50 \%$ of $\mathrm{MW}-20 \%$ or $30 \%$ of $\mathrm{MW}-30 \%$ that showed similar values. The significant interactive effect (Level x IMC) on firmness gives account for the decrease in firmness with the addition level for the MW-20\% treated flour while the addition of MW-30\% flour led to an increase of firmness with the addition level. A strong negative correlation between crumb firmness and specific volume $(\mathrm{p}<0.01 ; \mathrm{r}=-0.86)$ was obtained and confirmed by other works (Perez-Quirce et al., 2014; Ronda et al., 2015). 
Table 4: Effect of MW treated-rice flour substitution level (30\% and 50\% with respect to the total rice flour amount) depending on the treatment initial moisture content (MW-20\% and MW-30\%) on rice flour bread quality properties

\begin{tabular}{|c|c|c|c|c|c|c|c|c|c|c|c|}
\hline \multirow{2}{*}{$\begin{array}{l}\text { Bread } \\
\text { properties }\end{array}$} & \multirow{2}{*}{\multicolumn{2}{|c|}{ Level (\%): }} & \multirow{2}{*}{$\begin{array}{c}\text { Control } \\
0 \\
\end{array}$} & \multicolumn{2}{|c|}{ MW-20\% } & \multicolumn{2}{|c|}{ MW-30\% } & \multirow{2}{*}{ SE } & \multirow{2}{*}{$\begin{array}{c}\text { Factor } 1 \\
\text { Level }\end{array}$} & \multirow{2}{*}{$\begin{array}{c}\text { Factor } 2 \\
\text { IMC }\end{array}$} & \multirow{2}{*}{$\begin{array}{c}\text { Factor 1x2 } \\
\text { Level } x \text { IMC }\end{array}$} \\
\hline & & & & 30 & 50 & 30 & 50 & & & & \\
\hline Bake loss & $(\%)$ & & $19.13 \mathrm{a}$ & $21.19 \mathrm{~b}$ & $22.44 \mathrm{c}$ & $21.74 b$ & $21.54 \mathrm{~b}$ & 0.18 & $*$ & ns & $* *$ \\
\hline Firmness & $(\mathbf{N})$ & & $0.712 \mathrm{c}$ & $0.439 b$ & $0.345 \mathrm{ab}$ & $0.281 \mathrm{a}$ & $0.400 \mathrm{ab}$ & 0.058 & $\mathrm{~ns}$ & $\mathrm{~ns}$ & $*$ \\
\hline Springiness & & & $0.918 \mathrm{c}$ & $0.776 \mathrm{~b}$ & $0.626 \mathrm{a}$ & $0.659 \mathrm{a}$ & $0.596 \mathrm{a}$ & 0.031 & $* *$ & $*$ & ns \\
\hline Chewiness & $(\mathbf{N})$ & & $0.290 \mathrm{c}$ & $0.151 b$ & $0.100 \mathrm{a}$ & $0.081 \mathrm{a}$ & $0.107 \mathrm{ab}$ & 0.018 & ns & $*$ & $*$ \\
\hline Resilience & & & $0.230 \mathrm{~b}$ & $0.209 \mathrm{a}$ & $0.218 \mathrm{ab}$ & $0.204 \mathrm{a}$ & $0.210 \mathrm{ab}$ & 0.008 & $\mathrm{~ns}$ & ns & ns \\
\hline$\Delta$ Firmness-7 d & $(\mathrm{N})$ & & $3.00 \mathrm{c}$ & $2.18 b c$ & $1.30 \mathrm{ab}$ & $1.41 \mathrm{ab}$ & $0.91 \mathrm{a}$ & 0.27 & $*$ & ns & ns \\
\hline $\mathbf{L} *_{\text {crust }}$ & & & $53.2 \mathrm{a}$ & $56.0 \mathrm{ab}$ & $55.1 \mathrm{a}$ & $58.7 \mathrm{bc}$ & $60.5 c$ & 1.1 & ns & $* * *$ & ns \\
\hline $\mathbf{h}_{\text {crust }}$ & & & $60.5 \mathrm{a}$ & $69.7 c$ & $70.9 \mathrm{c}$ & $67.5 b$ & $69.8 \mathrm{c}$ & 0.56 & $* *$ & $* *$ & ns \\
\hline $\mathbf{L} *$ crumb & & & $66.4 b$ & $62.9 \mathrm{a}$ & $61.2 \mathrm{a}$ & $63.6 \mathrm{a}$ & $67.9 \mathrm{~b}$ & 0.87 & ns & $* * *$ & $* *$ \\
\hline $\mathbf{h}_{\text {crumb }}$ & & & $95.3 b$ & $95.7 \mathrm{~b}$ & $96.8 b$ & $92.6 \mathrm{a}$ & $92.7 \mathrm{a}$ & 0.56 & $\mathrm{~ns}$ & $* * *$ & $\mathrm{~ns}$ \\
\hline C* ${ }^{*}$ crumb & & & $6.1 \mathrm{~b}$ & $6.1 \mathrm{~b}$ & $5.3 \mathrm{a}$ & $6.5 \mathrm{~b}$ & $8.4 \mathrm{c}$ & 0.21 & $*$ & $* * *$ & $* * *$ \\
\hline
\end{tabular}

IMC: Initial Moisture Content of the treated flour. MW-20\%: Rice flour treated at 20\% of Initial Moisture Content; MW-30\%: Rice flour treated at 30\% of Initial Moisture Content. Different letters in the corresponding row indicate statistically significant differences between means at $\mathrm{p}<0.05$. SE: Pooled standard error obtained from ANOVA analysis. Analysis of variance and significance: $* * * p<0.001$. ** $p<0.01$. * $p<0.05$. ns: not significant. L*: luminosity, h: hue, $\mathrm{C}^{*}$ : chroma. 

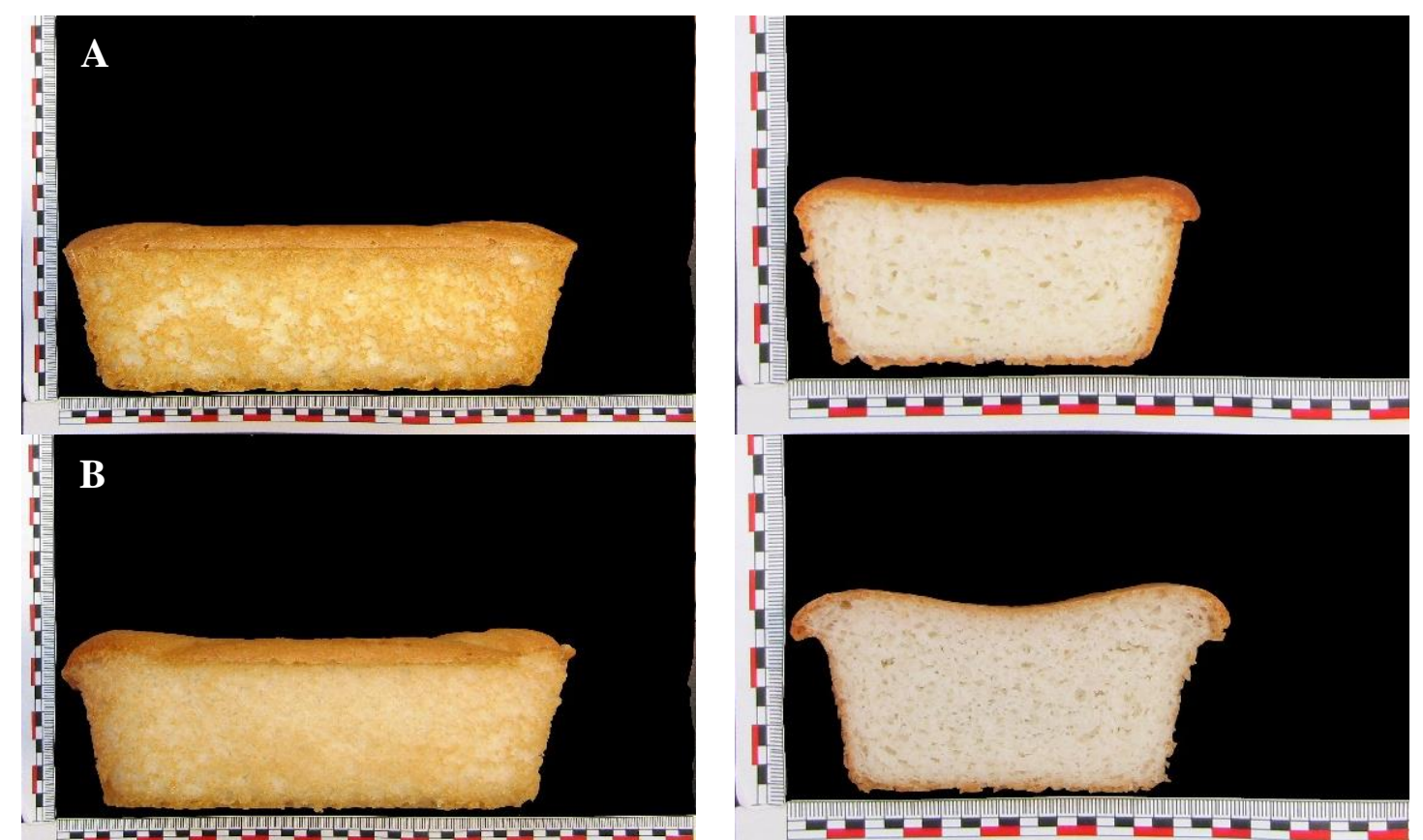

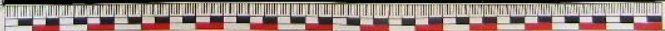
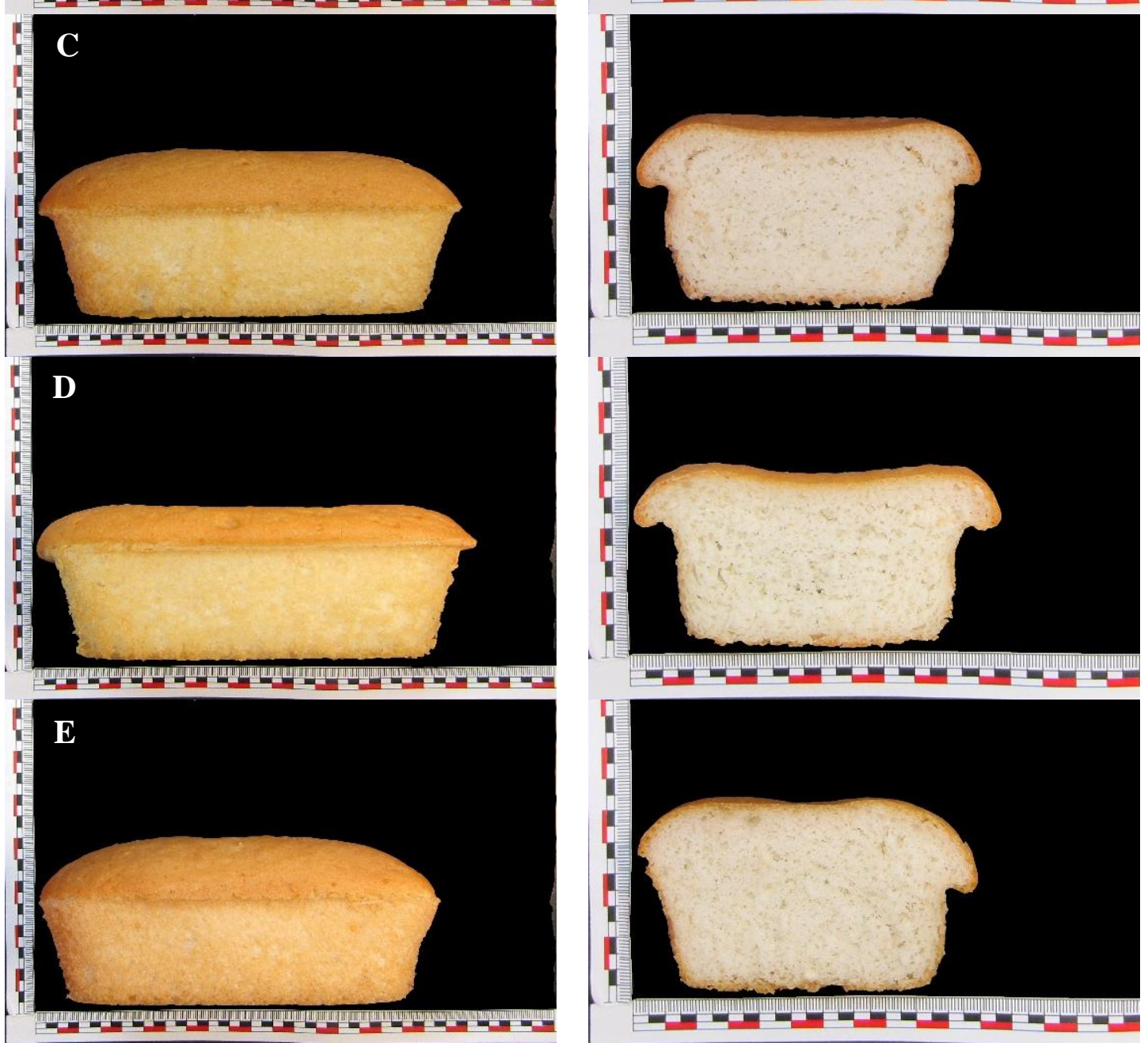

Figure 3. Effect of MW treated-rice flour addition on the external appearance and internal structures of gluten-free breads depending on the initial moisture content (IMC) of the flour before the treatment. A: Control 100\% rice flour, B: 30\% addition of treated-rice flour at 20\% IMC, C: $30 \%$ addition of treatedrice flour at 30\% IMC, D: $50 \%$ addition of treated-rice flour at 20\% IMC, E: 50\% addition of treated-rice flour at $30 \%$ IMC. 
A higher bread volume usually corresponds to higher amount of air retained in the dough structure during proofing and baking, which endorses a lower crumb firmness. Similar effect was observed for chewiness, probably because this parameter is mainly affected by hardness. Crumb springiness decreased with the addition of treated flours (Table 4). The decrease was dependent on the addition level and the IMC of the treated flour being more severe for the more intense treatment. However, resilience and cohesiveness, which relate to the bread crumb instant and retarded recovery capacity after a compression cycle were hardly affected by the flour treatment.

The bread hardening decreased significantly with the partial substitution of native flour by MW-treated rice flour. The change of the crumb firmness in 7 days decreased up to $70 \%$ for breads with $50 \%$ of $\mathrm{MW}-30 \%$ treated flour with respect to the control. Bread staling decreased significantly with the dose of MW treated flour regardless the IMC of the flour before the treatment. Such effect can be provoked by the greater bread volume and air amount entrapped in the crumb of breads made with treated flour. The cell wall of the crumb (which is the only one with the ability to harden) is in a smaller proportion within the surface area of the crumb sample under compression during texture measurements. This explains why breads with higher volume, higher crumb porosity and lower initial firmness, usually have lower hardening rate (Perez-Quirce et al., 2014). The nature of the cell wall of bread crumb, in particular its starch retrogradation kinetics and water binding capacity, are the other features that determine the hardening kinetics of bread crumbs (Ronda, Quilez, Pando and Roos, 2014). This is an important issue for coeliac patients, as gluten-free breads are generally more expensive and more difficult to access than traditional breads.

The breads made with MW-30\% treated-rice flour showed crusts with significantly higher $\mathrm{L}^{*}, \mathrm{~h}$, and $\mathrm{C}^{*}$ parameters than those of the control samples (Table 4). This means these breads were more yellowish, lighter and with more vivid colours (see Fig. 3). The breads made with MW-20\% treated flour, also showed more yellow hues in the crust than the control bread, although their lightness and saturation were similar to the bread made with $100 \%$ native flour. The colour of the crust results from the Maillard reaction during baking (Purlis, 2010). The heat treatment may affect precursors of these reactions, decreasing their concentration or availability to enter into reaction. In particular, proteins are denatured at the temperatures reached during the MW treatment. The colour of the crumb is mainly related to the colour of the ingredients (Villanueva et al., 2015). The high similarity among the colour of crumbs of all formulated breads 
means the MW treatment did not alter the colour of rice flours (data not shown) and they did not suffer any darkening. The visual inspection of loaves (Fig. 3) confirms the different impact of IMC of MW treated flours resulting in more developed loafs without central part fall. The visual evaluation also revealed the similar crumb colour of breads made with MW-treated flour vs the control confirming the low impact of treatment on flour colour change.

\section{Conclusions}

The MW assisted heat moisture treatment of rice flours resulted in substantial changes in dough viscoelastic and pasting properties. In consequence, treated flours showed a significantly different bread-making performance, improving all crucial parameters of bread quality. The doughs made with MW treated flours revealed higher consistency, more elastic behavior and resistance to deformation versus stress. All the breads obtained from treated-rice flour, regardless the IMC before the treatment and its level in substitution of native flour, resulted in higher specific volume, lower firmness and slower staling. The visual aspects, as bread loaf shape, crust color or crumb cells distribution were substantially improved, particularly with the use of MW-treated flour at $30 \%$ of IMC. The initial moisture content of MW treated flours impacted significantly on all bread-making performance and the rheological parameters of doughs. The MW assisted heat moisture treatment seems to be a valuable alternative to other types of rice flour modification being both effective and scalable.

\section{Acknowledgments}

The authors are grateful for the financial support of the Spanish Ministerio de Economía y Competitividad and the European Regional Development Fund (FEDER) (AGL2015-63849-C2-2-R) and of the Junta de Castilla y León/FEDER VA072P17. Joanna Harasym (MSCA) thanks the European Commission for the Individual Fellowship Grant (706102-BreadForAll) and Marina Villanueva thanks the Junta de Castilla y León for the doctorate grant.

\section{References}

American Association of Cereal Chemists (AACC). 2010a Method 44-19. Anonymous approved methods of the AACC (10th ed.). St. Paul: The Association.

American Association of Cereal Chemists (AACC). 2010b. Method 76-21.01. 
Anonymous approved methods of the AACC (10th ed.). St. Paul: The Association.

Amin, T., Naik, H.R., Hussain, S.Z., Rather, A.H., Murtaza, I., \& Dar, B.N. 2017. Structural properties of high-protein, low glycaemic index (GI) rice flour. International Journal of Food Properties, 20, 2793-2804.

Anderson, A.K., Guraya, H.S. 2006. Effects of microwave heat-moisture treatment on properties of waxy and non-waxy rice starches. Food Chemistry, 97, 318-323.

BeMiller, J.N., Huber, K.C. 2015. Physical modification of food starch functionalities. Annual Review of Food Science and Technology, 6, 19-69.

Bourekoua, H., Benatallah, L., Zidoune, M.N., Rosell, C.M. 2016. Developing gluten free bakery improvers by hydrothermal treatment of rice and corn flours. LWT Food Science and Technology, 73, 342-350.

Cappa, C., Barbosa-Cánovas, G.V., Lucisano, M., Mariotti, M. 2016. Effect of high pressure processing on the baking aptitude of corn starch and rice flour. LWT Food Science and Technology, 73, 20-27.

Cornejo, F., Rosell, C.M. 2015. Physicochemical properties of long rice grain varieties in relation to gluten free bread quality. LWT - Food Science and Technology, 62, 1203-1210.

Crockett, R., Ie, P., Vodovotz, Y. 2011. Effects of soy protein isolate and egg white solids on the physicochemical properties of gluten-free bread. Food Chemistry. 129, 84-91.

Demirkesen, I., Mert, B., Sumnu, G., Sahin, S. 2010. Rheological properties of glutenfree bread formulations. Journal of Food Engineering, 96, 295-303.

Lazaridou, A., Duta, D., Papageorgiou, M., Belc, N., \& Biliaderis, C. G. 200. Effects of hydrocolloids on dough rheology and bread quality parameters in gluten-free formulations. Journal of Food Engineering, 79, 1033-1047.

Lewandowicz, G., Jankowski, T., Fornal, J. 2000. Effect of microwave radiation on physico-chemical properties and structure of cereal starches. Carbohydrate Polymers, 42, 193-199.

Majzoobi, M., Pesaran, Y., Mesbahi, G., Farahnaky, A. 2016. Evaluation of the effects of hydrothermal treatment on rice flour and its related starch. International Journal of Food Properties, 19, 2135-2145.

Marston, K., Khouryieh, H., Aramouni, F. 2016. Effect of heat treatment of sorghum flour on the functional properties of gluten-free bread and cake. LWT - Food Science and Technology, 65, 637-644.

Olayinka, O.O., Adebowale, K.O., Olu-Owolabi, B.I. 2008. Effect of heat-moisture treatment on physicochemical properties of white sorghum starch. Food Hydrocolloids, 22. 225-230.

Pérez-Quirce, S., Collar, C., Ronda, F. 2014. Significance of healthy viscous dietary fibres on the performance of gluten-free rice-based formulated breads. International Journal of Food Science and Technology, 49, 1375-1382.

Pérez-Quirce, S., Ronda, F., Lazaridou, A., Biliaderis, C.G. 2017. Effect of microwave radiation pretreatment of rice flour on gluten-free breadmaking and molecular size of $\beta$-lucans in the ortified reads. Food and Bioprocess Technology, 10, 1412-1421.

Pinkrova, J., Hubackova, B., Kadlec, P., Prihoda, J., Bubnik, Z. 2003. Changes of 
Starch during Microwave Treatment of Rice. Czech J. Food, 21, 176-184.

Puncha-Arnon, S., Uttapap, D. 2013. Rice starch vs. rice flour: Differences in their properties when modified by heat-moisture treatment. Carbohydrate Polymers, 91, 85-91.

Purlis, E. 2010. Browning development in bakery products-a review. Journal of Food Engineering, 99, 239-249.

Qin, Y., Liu, C., Jiang, S., Cao, J., Xiong, L., Sun, Q. 2016. Functional properties of glutinous rice flour by dry-heat treatment. PLoS One 11, e0160371.

Renzetti, S., Rosell, C.M. 2016. Role of enzymes in improving the functionality of proteins in non-wheat dough systems. Journal of Cereal Science, 67, 35-45.

Ronda, F., Pérez-Quirce, S., Angioloni, A., Collar, C. 2013. Impact of viscous dietary fibres on the viscoelastic behaviour of gluten-free formulated rice doughs: A fundamental and empirical rheological approach. Food Hydrocolloids, 32, 252262.

Ronda, F., Pérez-Quirce, S., Lazaridou, A., Biliaderis, C.G. 2015. Effect of barley and oat $\beta$-glucan concentrates on gluten-free rice based doughs and bread characteristics. Food Hydrocolloids, 48, 197-207.

Ronda, F., Pérez-Quirce, S., \& Villanueva, M. 2017. Rheological properties of glutenfree bread doughs. Relationship with bread quality. In J. Ahmed, P. Ptaszek, \& S. Basu (Eds.). Advances in food rheology and applications (pp. 297-334). Cambridge, UK: ELSEVIER.

Ronda, F., Quilez, J., Pando, V., \& Roos, Y. 2014. Fermentation time and fiber effects on recrystallization of starch components and staling of bread from frozen partbaked bread. Journal of Food Engineering, 131, 116-123.

Ronda, F., Villanueva, M., Collar, C. 2014. Influence of acidification on dough viscoelasticity of gluten-free rice starch-based dough matrices enriched with exogenous protein. LWT - Food Science and Technolology, 59, 12-20.

Rosell, C.M., Barro, F., Sousa, C., Mena, M.C. 2014. Cereals for developing gluten-free products and analytical tools for gluten detection. Journal of Cereal Science, 59, 354-364.

Sivaramakrishnan, H., Senge, B., \& Chattopadhyay, P. K. 2004. Rheological properties of rice dough for making rice bread. Journal of Food Engineering, 62, 37-45.

Skendi, A., Papageorgiou, M., Biliaderis, C.G. 2009. Effect of barley b-glucan molecular size and level on wheat dough rheological properties. Journal of Food Engineering, 91, 594-601

Villanueva, M., Mauro, R.R., Collar, C., Ronda, F. 2015. Acidification of proteinenriched rice starch doughs: effects on breadmaking. European Food Research and Technology, 240, 783-794.

Villanueva, M., De Lamo, B., Harasym, J., Ronda, F. 2018c. Microwave radiation and protein addition modulate hydration, pasting and gel rheological characteristics of rice and potato starches. Carbohydrate Polymers. 201, 374-381

Villanueva, M., Harasym, J., Muñoz, J.M., Ronda, F. 2018a. Microwave absorption capacity of rice flour. Impact of the radiation on rice flour microestructure, thermal and viscometric properties. Journal of Food Engineering, 224, 156-164. 
Villanueva, M., Mauro, R. R., Collar C., \& Ronda, F. 2015. Acification of proteinenriched rice starch doughs: Effects on breadmaking. European Food Research and Technology, 240, 783-794.

Villanueva, M., Pérez-Quirce, S., Collar, C., Ronda, F. 2018b. Impact of acidification and protein fortification on rheological and thermal properties of wheat, corn, potato and tapioca starch-based gluten-free bread doughs. LWT- Food Science and Technology, 96, 446-454.

Watcharatewinkul, Y., Puttanlek, C., Rungsardthong, V., Uttapap, D. 2009. Pasting properties of a heat-moisture treated canna starch in relation to its structural characteristics. Carbohydrate Polymers, 75, 505-511.

Wu, Y. B., Dong, Y., \& Xu, B. 2008. Comparative research on the stabilization methods of wheat germ. Science and Technology of Food Industry, 6, 34-37.

Xu, E., Pan, X., Wu, Z., Long, J., Li, J., Xu, X., Jin, Z., Jiao, A. 2016. Response surface methodology for evaluation and optimization of process parameter and antioxidant capacity of rice flour modified by enzymatic extrusion. Food Chemistry, 212, 146154.

Xu, Bin, Zhou, Shi-Long, Miao, Wen-Juan, Gao, Chao, Cai, mIng-Jing \& Dong, Ying. 2013. Study on the stabilization effect of continuous microwave on wheat germ. Journal of Food Engineering, 117, 1-7.

Yano, H., Fukui, A., Kajiwara, K., Kobayashi, I., Yoza, K.-I., Satake, A., et al. 2017. Development of gluten-free rice bread: Pickering stabilization as a possible batterswelling mechanism. LWT - Food Science and Technology, 79, 632-639.

Zavareze, E.D.R., Dias, A.R.G. 2011. Impact of heat-moisture treatment and annealing in starches: a review. Carbohydrate Polymers, 83, 317-328.

Ziobro, R., Witczak, T., Juszczak, L., Korus, J. 2013. Supplementation of gluten-free bread with non-gluten proteins. Effect on dough rheological properties and bread characteristic. Food Hydrocolloids, 32, 213-220. 